\title{
Could potentially calprotectin be a promising biomarker to oracle biologic therapy response in rheumatoid arthritis?
}

Rania Abd El-Hamid El-Kady ${ }^{1,2^{*}}$, Ayah Fathy ${ }^{1}$, Talaat Othman ${ }^{1}$ and Eman Hafez ${ }^{3}$

\begin{abstract}
Background: The advent of novel biologic agents for the treatment of rheumatoid arthritis (RA) has proven to be highly productive. Nonetheless, high cost, side effects, and unresponsiveness to these agents dictates the assignment of biomarkers that can foretell treatment response. Currently, calprotectin (a member of the S100 protein family) is amongst the enormously studied candidates in this perspective. Yet, conflicting results have been published. The main purpose of this study was to explore the role of serum concentration of calprotectin to predict the response to biological therapy in RA patients, so as to customize RA treatment.

Results: Baseline serum calprotectin levels were significantly higher in RA patients compared to the control subjects $(P$ value $<0.001)$. After receiving biologic therapy, a remarkable reduction $(P<0.001)$ in serum calprotectin was noted in RA cohort. Moreover, no correlation was found between the 28 joint count disease activity score (DAS28) and serum calprotectin levels neither before or after biologics. Intriguingly, no statistically significant association was detected between circulating calprotectin level and response to biological therapy.

Conclusion: Serum calprotectin concentrations could not be used as a biomarker to forecast clinical response to biological therapy in RA patients. However, further studies involving larger cohort of RA patients should be carried out to deliver more insight in this regard.
\end{abstract}

Keywords: Rheumatoid arthritis, Calprotectin, Biomarker, Predict, Biologic therapy, Disease activity, Prospective

\section{Background}

Rheumatoid arthritis (RA) is a common, long-term, autoimmune, inflammatory disease that may cause progressive joint destruction and malformation, thus provoking a functional debility and poor quality of life [1]. Though the exact etiology of RA is yet undetermined, an interplay between genetic predisposition, environmental and hormonal mediators seems to trigger the disease development [2]. Aberrations in the cellular and humoral arms of the immune system result into the formation of

\footnotetext{
*Correspondence: raniael_kady@yahoo.com

${ }^{2}$ Department of Pathological Sciences, Fakeeh College for Medical

Sciences, Jeddah 2537, Kingdom of Saudi Arabia

Full list of author information is available at the end of the article
}

autoantibodies, especially rheumatoid factor (RF) and anti-cyclic citrullinated peptide (anti-CCP) antibodies [3].

At present, immunomodulatory agents known as disease-modifying anti-rheumatic drugs (DMARDs) are generally available for the treatment of RA [4]. Conventional synthetic DMARDs include hydroxychloroquine, methotrexate, leflunomide, and sulfasalazine [5]. On top of that, targeted synthetic DMARDs (tsDMARDs), e.g., Janus kinase (JAK) inhibitors are considered another treatment option for RA [6]. On the other hand, the most commonly used biologic DMARDs (bDMARDs) include etanercept, infliximab, and adalimumab (inhibitors of tumor necrosis factor- $\alpha$; anti-TNF- $\alpha$ ) [7], tocilizumab (a humanized monoclonal antibody against the interleukin-6 receptor; IL-6R) [8], rituximab (a chimeric 
anti-CD20 monoclonal antibody) [9], abatacept (costimulation blocker) [10], and anakinra (a recombinant inhibitor of interleukin-1; IL-1) [11]. Importantly, bDMARDs are usually proposed for treatment of RA patients who fail to respond to conventional DMARDs with clinical or radiologic evidence of disease progression [12].

In clinical occasions, bDMARDs are often administered on a 'trial-and-error' manner and each patient does not respond likewise to the same medications [13]. Stratifying patients to amplify the likelihood of a strong treatment outcome will subsequently minimize the risk of unsuccessful treatment adverse effects and escalate cost-effectiveness which is of particular concern for the healthcare system. Accordingly, plenty of researches have been brought off to identify biomarkers that can predict the response to bDMARDs [14].

Calprotectin, a member of the S100 protein family, is among the widely investigated biomarkers in this context [15]. It is a heterodimeric complex of 2 non-covalently associated calcium-binding proteins, S100A8 (myeloidrelated protein; MRP 8) and S100A9 (MRP 14). Calprotectin is located in the cytoplasm of neutrophils and monocytes. When released, it functions as a damageassociated molecular pattern (DAMP) or alarmin, via toll-like receptor 4 (TLR4) activation [16].

Calprotectin was specified this name owing to its protective role in epithelial defense as well as its bactericidal and fungicidal properties [17]. Normally, it is present in the serum at a concentration that varies from 0.1 to 1.6 $\mu \mathrm{g} / \mathrm{ml}$ and is increased in many disorders such as infection, inflammation or cancer. The low molecular weight $(36.5 \mathrm{kDa})$ of this protein allows its circulation from the site of inflammation to the blood. It is proposed that serum concentrations of calprotectin appear to mirror synovial levels with a ratio of 1:2-3 [18].

In the past few years, a plethora of studies highlighted the role of calprotectin as a biomarker for response to bDMARDs among RA patients. Undesirably, contradictory results have been disclosed. Thereby, this study was designed in an attempt to assess the worth of serum concentration of calprotectin as an oracle to the response to bDMARDs, so as to personalize RA treatment.

\section{Methods}

\section{Study design, subjects, and setting}

This prospective cohort study enrolled a total of 25 consecutive adult patients (16 females and 9 males, mean age \pm SD; $41.32 \pm 10.04$ years) who fulfilled the American College of Rheumatology/European League Against Rheumatism (ACR/EULAR) 2010 classification criteria for RA [19]. The study cohort was recruited in the period from January 2019 to December 2019 from the Outpatient Clinics of Rheumatology and Rehabilitation in
Mansoura University Hospital (MUH), Egypt. Additional 30 age- and gender-matched healthy individuals were included as a control group.

Our sample size was calculated using $G$ "power program [20]. A previous study concluded that the mean calprotectin level \pm SD was $190.2 \pm 80.4 \mu \mathrm{g} / \mathrm{dl}$ in the study group and $63.1 \pm 20.3 \mu \mathrm{g} / \mathrm{dl}$ in the control group [21] with an alpha error $=0.05$ and a study power $=0.95$, accordingly the required sample size was at least 7 per group.

\section{Exclusion criteria}

Patients $<18$ years, pregnant or nursing females, and RA patients with any other concomitant autoimmune disease or current or past history of malignancy were excluded from the study. Furthermore, patients with any form of current acute or chronic infection and organ transplant recipients were not eligible to our study.

\section{Patients' assessment}

Thorough history taking and clinical evaluation was done for each patient. Disease activity was assessed by the 28 joint count disease activity score (DAS28) and C-reactive protein (CRP) at baseline and 12 weeks after receiving bDMARDs. DAS28 was measured using swollen joint count (SJC) and tender joint count (TJC) as well as the patient rating for general health on a $100-\mathrm{mm}$ visual analog scale (VAS). A DAS $28<2.6$ indicates remission, 2.6-3.2 low disease activity, 3.2-5.1 intermediate disease activity, and $>5.1$ high disease activity [22].

Complete blood count (CBC), liver function tests, kidney function tests, serum C-reactive protein (CRP), rheumatoid factor IgM (RF), erythrocyte sedimentation rate (ESR), and anti-cyclic citrullinated peptide (anti-CCP) were assessed using the currently available hospital laboratory protocols.

\section{Determination of serum calprotectin concentrations in the study subjects}

Serum calprotectin levels were measured in the enrolled $25 \mathrm{RA}$ patients at baseline and 12 weeks after receipt of bDMARDs, as well as in the 30 healthy controls. About $3 \mathrm{ml}$ fasting, peripheral venous blood specimens were collected from each participant. Blood samples were centrifuged immediately after being collected to prevent the release of calprotectin from activated leucocytes and sera were subsequently stored at $-80{ }^{\circ} \mathrm{C}$ until the analysis. The assessment was done using the commercially available enzyme-linked immune-sorbent assay (ELISA) kit according to manufacturer's guidelines (Shanghai Korain Biotech CO., Ltd., China). All values were expressed in $\mathrm{ng} / \mathrm{ml}$. 


\section{Biologic DMARDs' protocols for RA cohort}

Approximately $80 \%$ of the included RA patients in this study were receiving bDMARDs for the first time and $20 \%$ received previous courses of bDMARDs, but they were starting a new course at the time of their enrollment. The prescribed drugs included infliximab (remicade); $1-3 \mathrm{mg} / \mathrm{kg}$ intravenous infusion $0,2,6$ weeks, maintenance every 8 weeks (36\% of RA patients), etanercept (enbrel); $50 \mathrm{mg}$ subcutaneous every week (28\%), adalimumab (humera); $40 \mathrm{mg}$ subcutaneous every other week (20\%), tocilizumab (actemra); 4-8 $\mathrm{mg} / \mathrm{kg}$ intravenous infusion every month $(12 \%)$ and golimumab (simponi); $50 \mathrm{mg}$ subcutaneous every month (4\%).

The response to bDMARDs was recorded after 3 months according to the commonly applied EULAR response criteria [23] as follows: good responders; having a DAS2 $8 \leq 3.2+$ a decrease in DAS28 $>1.2$, moderate responders; having either DAS28 $\leq 3.2+$ a decrease in DAS28 $>0.6$ and $\leq 1.2$ or DAS2 $\leq 5.1>3.2+$ a decrease in DAS28 $>0.6$ or DAS28 > $5.1+$ a decrease in DAS28 $>1.2$, and non-responders; having either a decrease in DAS28 $<0.6$ or a DAS28 $>5.1+$ a decrease in DAS28 $\leq$ 1.2 .

\section{Statistical analysis}

Data were processed and analyzed using SPSS program version 24.0 for Windows (SPSS Inc., Chicago, IL, USA). Qualitative data were described as numbers and percentages with Pearsons chi-square $\left(\chi^{2}\right)$ test used for comparison, meanwhile Fisher's exact test was used as a correction for $\chi^{2}$ test when $>25 \%$ of cells have count $<5$ in $2 \times 2$ tables. Quantitative data were described using median and range for non-parametric data and mean \pm standard deviation (SD) for parametric data after testing normality using Kolmogrov-Smirnov test. The Student $t$ test was used to compare between 2 independent groups (parametric). The Mann-Whitney $U$ test was used for comparison between groups (non-parametric) and the Wilcoxon signed rank test to compare between the 2 studied periods.

The Spearman's rank-order correlation coefficient $\left(r_{\mathrm{s}}\right)$ was used to determine the strength and direction of a linear relationship between 2 non-normally distributed continuous variables. The Kruskal-Wallis (KW) test was done to detect the possible association between serum calprotectin level and response to biological therapy. Receiver operating characteristic (ROC) curves were plotted to assess the diagnostic accuracy of serum calprotectin for discrimination of patients with high and moderate disease activity and to compare the diagnostic accuracy of calprotectin, CRP and ESR in this regard.
Significance of the obtained results was judged at $P$ values $\leq 0.05[24]$.

\section{Results}

The demographic, clinical, radiological, and laboratory parameters of RA patients are shown in Table 1. Overall, a total of 25 patients with RA (mean age $41.32 \pm 10.04$ years, $64 \%$ females), and 30 healthy control subjects (mean age $38.53 \pm 9.93$ years, $70 \%$ females) were enrolled in the current study. The mean disease duration was 8.32 \pm 5.45 years from preliminary clinical presentation.

Baseline serum calprotectin levels were significantly higher in RA patients compared to the control subjects ( $P$ $<0.001$ ). After commencing biologic therapy, a substantial reduction in serum calprotectin was noted among the enrolled patients with a statistically significant difference $(P<0.001)$. Values are illustrated in Figs. 1 and 2, respectively.

At baseline, 24\% of the enrolled patients exhibited a moderate DAS28 and 76\% had a high score. After initiating biologics, $68 \%$ and $32 \%$ of the patients showed moderate and high DAS28, respectively $(P<0.001)$. Also, a significant decline in the DAS28 among the enrolled patients after receipt of bDMARDs was noted $(P<0.001)$ as shown in Fig. 3.

Table 1 Baseline features of rheumatoid arthritis cohort

\begin{tabular}{|c|c|}
\hline Parameters & RA patients $(n=25)$ \\
\hline Age (years); mean $\pm \mathrm{SD}$ & $41.32 \pm 10.04$ \\
\hline \multicolumn{2}{|l|}{ Gender (number, percentage) } \\
\hline -Females & $16(64 \%)$ \\
\hline -Males & $9(36 \%)$ \\
\hline Disease onset (years); mean \pm SD & $33 \pm 11.29$ \\
\hline Disease duration (years); mean \pm SD & $8.32 \pm 5.45$ \\
\hline Morning stiffness (min); mean \pm SD & $41 \pm 25.81$ \\
\hline Swollen joints & $6.72 \pm 3.38$ \\
\hline $\mathrm{ESR}(\mathrm{mm} / \mathrm{h}) ;$ mean $\pm \mathrm{SD}$ & $65.76 \pm 29.24$ \\
\hline $\mathrm{CRP}(\mathrm{mg} / \mathrm{l}) ;$ mean $\pm \mathrm{SD}$ & $53.61 \pm 24.91$ \\
\hline DAS28; mean $\pm S D$ & $5.91 \pm 0.98$ \\
\hline RF (lgM) positivity & $21(84.0 \%)$ \\
\hline $\mathrm{RF}(\mathrm{IU} / \mathrm{ml}) ;$ mean $\pm \mathrm{SD}$ & $133.76 \pm 88.21$ \\
\hline Anti-CCP positivity & $15(60 \%)$ \\
\hline Anti-CCP $(\mathrm{RU} / \mathrm{ml}) ;$ mean $\pm \mathrm{SD}$ & $322.20 \pm 112.60$ \\
\hline \multicolumn{2}{|l|}{ bDMARDs at inclusion } \\
\hline -Infliximab (remicade) & $9(36 \%)$ \\
\hline -Etanercept (enbrel) & $7(28 \%)$ \\
\hline -Adalimumab (humera) & $5(20 \%)$ \\
\hline -Tocilizumab (actemra) & $3(12 \%)$ \\
\hline -Golimumab (simponi) & $1(4 \%)$ \\
\hline
\end{tabular}

Abbreviations: $C R P$ C-reactive protein, ESR erythrocyte sedimentation rate, CCP cyclic citrullinated peptide, $R F$ rheumatoid factor, $b D M A R D s$ biologic diseasemodifying anti-rheumatic drugs, $n$ number, $S D$ standard deviation 


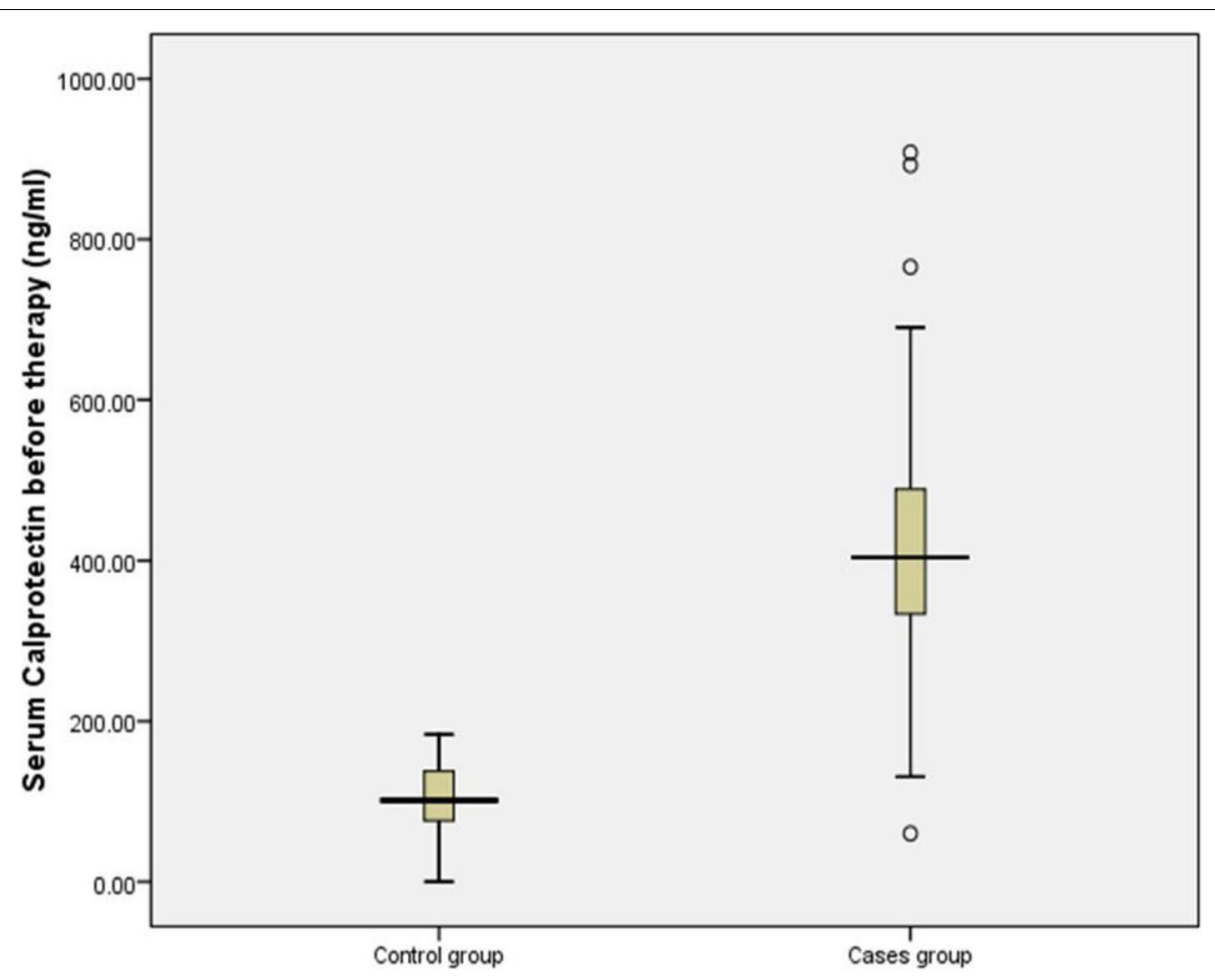

Fig. 1 Box and Whisker plot of baseline serum calprotectin concentrations among the study cohort. Rheumatoid arthritis patients showed remarkably higher levels $[404.1(60.0-908.2 \mathrm{ng} / \mathrm{ml})]$ as compared to the healthy controls $[101.45(0.0-183.7 \mathrm{ng} / \mathrm{ml})] ; P<0.001$

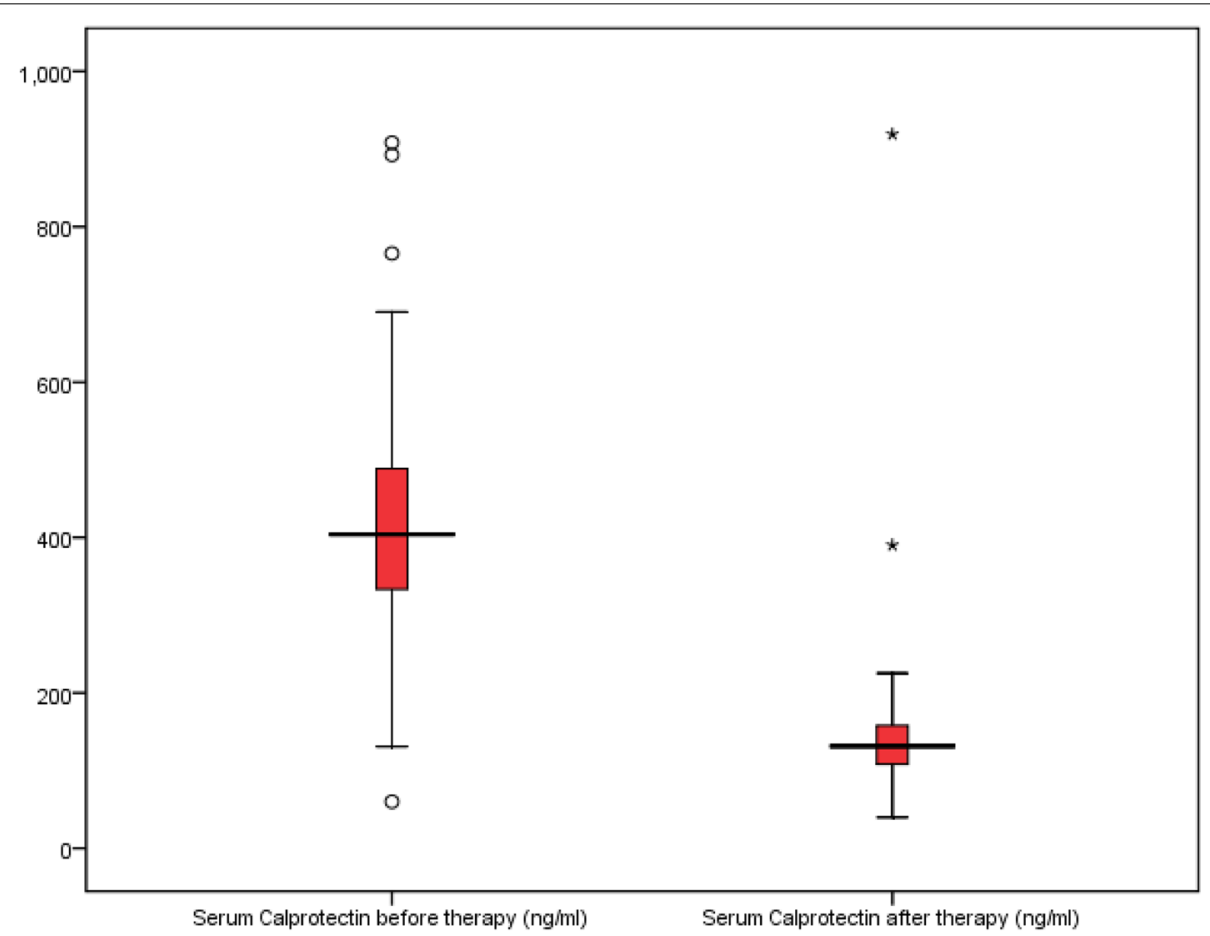

Fig. 2 Box and Whisker plot of serum calprotectin before and after therapy among rheumatoid arthritis patients. Three months after biologic therapy, a significant decline in serum calprotectin from $404.1(60.0-908.2 \mathrm{ng} / \mathrm{ml})$ to $131.70(39.9-171.73 \mathrm{ng} / \mathrm{ml})$ was observed $(P<0.001)$ 


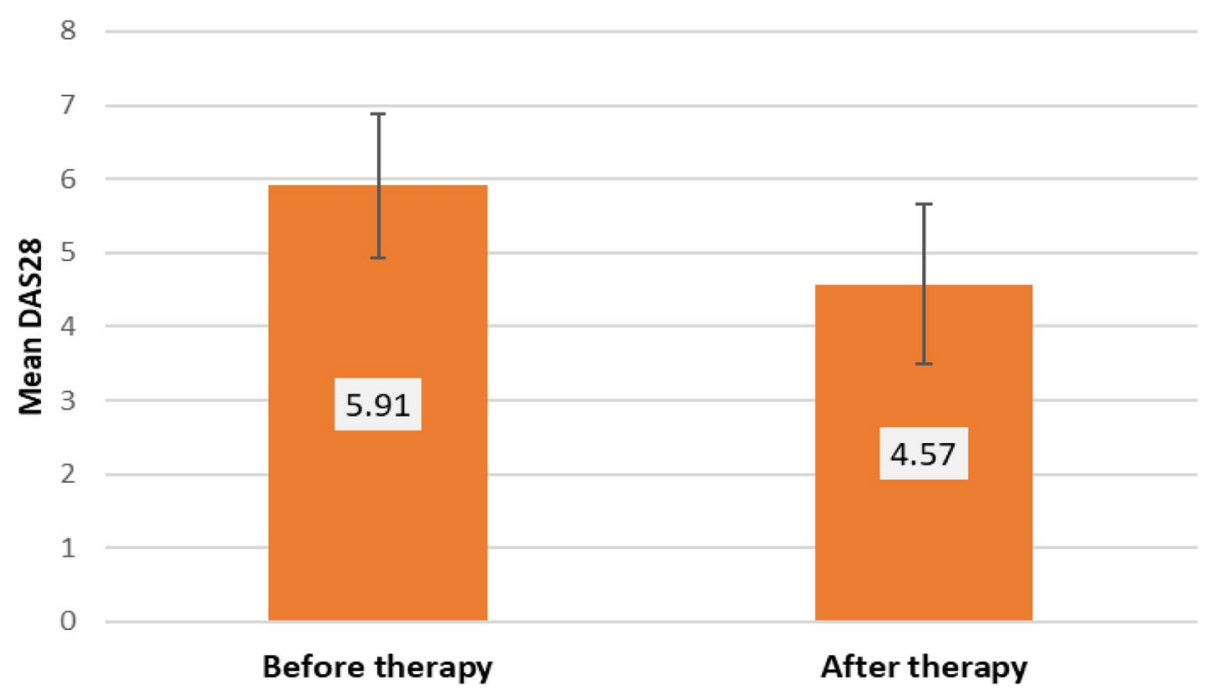

Fig. 3 Disease activity score 28 (DAS28) among the enrolled rheumatoid arthritis patients. There was a statistically significant decline in the mean DAS28 amongst RA patients from $5.91 \pm 0.98$ to $4.57 \pm 1.08 \mathrm{ng} / \mathrm{ml}$ three months after initiation of biologic therapy $(P<0.001)$

Table 2 Correlation between DAS28 and serum calprotectin levels

\begin{tabular}{lll}
\hline & DAS28 before bDMARDs & \\
Serum calprotectin (ng/ & $r_{\mathrm{s}}$ & -0.091 \\
ml) before bDMARDs & $P$ & 0.667 \\
& DAS28 after bDMARDs & \\
Serum calprotectin (ng/ & $r_{\mathrm{s}}$ & 0.053 \\
$\mathrm{ml}$ ) after bDMARDs & $P$ & 0.801 \\
\hline
\end{tabular}

DAS28 Disease Activity Score 28, bDMARDs biologic disease-modifying antirheumatic drugs, $r_{\mathrm{s}}$ Spearman's correlation coefficient, $P \leq 0.05$; statistically significant

In this study, no correlation was found between DAS28 and serum calprotectin levels neither before or after bDMARDs (results are presented in Table 2). Furthermore, a ROC curve was plotted to demonstrate validity of serum calprotectin in discriminating high disease activity patients from those with moderate activity. Before starting bDMARDs, the area under the curve (AUC) was 0.654 (95\% CI $0.437-0.872$ ); $P=0.221$, whereas after therapy, the AUC was 0.522 (95\% CI 0.252-0.792); $P=$ 0.861 (data are shown in Fig. 4).

Additional ROC curve was designed to compare the diagnostic accuracy of serum calprotectin, CRP and ESR for discrimination of patients with high and moderate disease activity (Fig. 5). The ROC analysis showed that at a cutoff point of $397.05 \mathrm{ng} / \mathrm{ml}$, calprotectin showed a maximum AUC of 0.608 (95\% CI 0.372-0.845); $P=0.401$, whereas CRP at a cutoff point of $60 \mathrm{mg} / \mathrm{l}$ showed an AUC $=0.704$ (95\% CI 0.457-0.952); $P=0.114$. Besides, ESR at a cutoff point of $67.5 \mathrm{~mm} / \mathrm{h}$ had an AUC $=0.579(95 \% \mathrm{CI}$ $0.336-0.823) ; P=0.540$.
Three months after receiving bDMARDs, 3 EULAR response phenotypes were obtained in the included RA patients; 1 was good responder (4\%), 18 were moderate responders $(72 \%)$ and 6 were non-responders (24\%). The median serum calprotectin level in the good responder was $140.55 \mathrm{ng} / \mathrm{ml}$, in the moderate responders $136.80 \mathrm{ng} /$ $\mathrm{ml}$ and in the non-responders $96.18 \mathrm{ng} / \mathrm{ml}$. No statistically significant association was found between serum calprotectin level and response to biological therapy. Of note, patients that developed a moderate response to biologic therapy were the only group to show a significant reduction in their serum calprotectin levels after receipt of biologics. Results are presented in Table 3.

\section{Discussion}

The birth of new era of therapeutics in RA is one of the foremost histrionic alterations in the future of patients with established RA. Though the list of bDMARDs is continually escalating, no scientifically based approach is currently available for selecting which drug a patient should receive [25]. Therefore, several studies have been undertaken to identify consistent biomarkers, that can be used to foretell treatment outcome [26]. Nowadays, serum calprotectin has acquired endorsement in this aspect. However, there is no consensus in the literature in terms of the correlation between circulating calprotectin levels and response to bDMARDs. For that reason, we carried out this study to investigate the prognostic value of serum calprotectin for clinical response to bDMARDs in patients with RA.

In this 1-year, prospective, cohort study of $25 \mathrm{RA}$ patients, the baseline serum calprotectin levels were 


\section{ROC Curve}

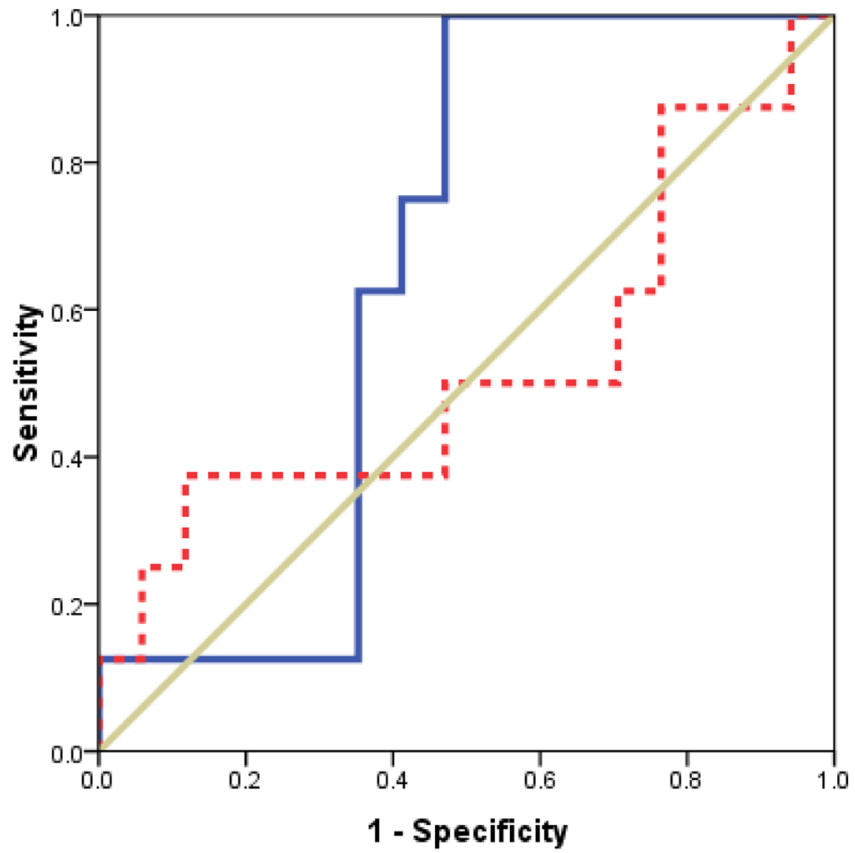

Source of the Curve

Serum Calprotectin

before therapy (ng/ml)

Serum Calprotectin after

- therapy (ng/ml)

- Reference Line

Fig. 4 Receiver operating characteristic (ROC) curve for serum calprotectin levels before and after biologic therapy. Before starting bDMARDs, the area under the curve (AUC) was $0.654(95 \% \mathrm{Cl} 0.437-0.872) ; P=0.221$, whereas after therapy, the AUC was $0.522(95 \% \mathrm{Cl} 0.252-0.792) ; P=0.861$

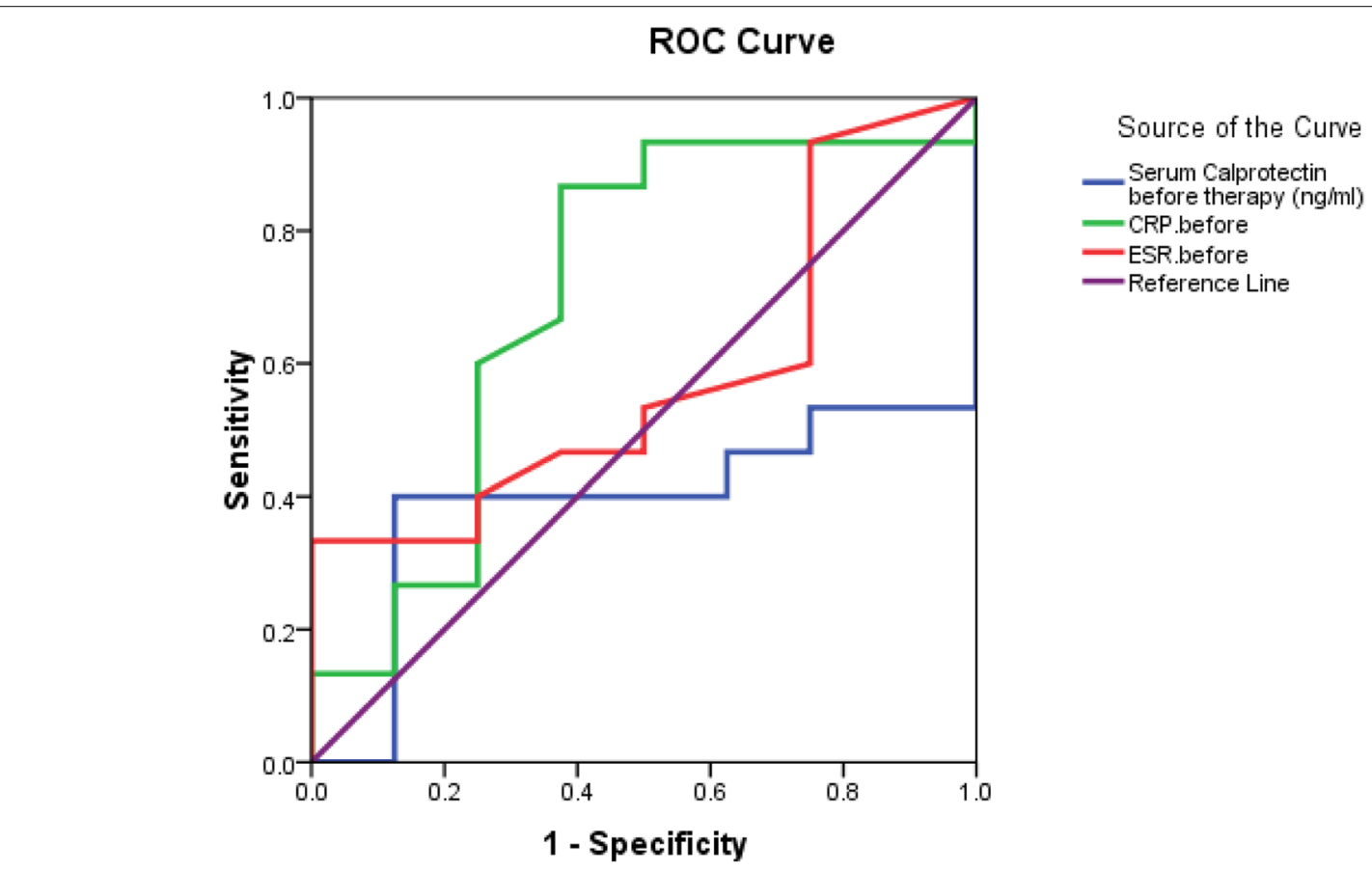

Diagonal segments are produced by ties.

Fig. 5 Receiver operating characteristic (ROC) curve for serum calprotectin levels, CRP and ESR to discriminate patients with high and moderate disease activity. The ROC analysis showed that at a cutoff point of $397.05 \mathrm{ng} / \mathrm{ml}$, calprotectin showed a maximum AUC of 0.608 (95\% Cl 0.3720.845); $P=0.401$, whereas CRP at a cutoff point of $60 \mathrm{mg} / \mathrm{l}$ showed an $\mathrm{AUC}=0.704$ (95\% Cl 0.457-0.952); $P=0.114$. Besides, ESR at a cutoff point of $67.5 \mathrm{~mm} / \mathrm{h}$ had an $\mathrm{AUC}=0.579(95 \% \mathrm{Cl} 0.336-0.823) ; P=0.540$ 
Table 3 Association between serum calprotectin and response to biologic therapy

\begin{tabular}{|c|c|c|c|c|}
\hline & Non-responders $(n=6)$ & Moderate responders $(n=18)$ & Good responder $(n=1)$ & Test of significance \\
\hline \multicolumn{5}{|c|}{ Serum calprotectin before treatment $(\mathrm{ng} / \mathrm{ml})$} \\
\hline Median (range) & $388.35(60.0-486.0)$ & $415.65(130.8-908.2)$ & $488.7(488.7-488.7)$ & $P=0.526^{*}$ \\
\hline \multicolumn{5}{|c|}{ Serum calprotectin after treatment $(\mathrm{ng} / \mathrm{ml})$} \\
\hline \multirow[t]{2}{*}{ Median (range) } & $96.18(39.9-919.05)$ & $136.80(45.45-390.20)$ & $140.55(140.55-140.55)$ & $P=0.746^{*}$ \\
\hline & $\begin{array}{l}z=0.734 \\
P=0.463\end{array}$ & $\begin{array}{l}z=3.72 \\
P<0.001^{* *}\end{array}$ & $\begin{array}{l}\text { NA } \\
\text { (Only one case) }\end{array}$ & \\
\hline$\%$ of reduction & $37.5 \%$ & $68.7 \%$ & $71.2 \%$ & \\
\hline
\end{tabular}

Abbreviations: NA not applicable, $n$ number

${ }^{* *} P \leq 0.05$; statistically significant

${ }^{*}$ Calculated using Kruskal-Wallis test

significantly higher in RA patients [404.1 (60.0-908.2 ng/ $\mathrm{ml})]$ as compared to the healthy subjects [101.45 $(0.0-$ $183.7 \mathrm{ng} / \mathrm{ml}$ )]; $P<0.001$. This result is analogous to the findings of an earlier study [27]. It is proposed that during inflammatory response, calprotectin which is a key leucocyte-related cytosolic protein, is secreted by the primed leucocytes at the site of the inflamed joint, so it is a definite biomarker of joint inflammation [28].

Interestingly, a noteworthy reduction in serum calprotectin level $(P<0.001)$ was perceived among the engaged RA cohort 3 months after commencement of biologic therapy. In line with our finding, Choi et al. 2014 [29] and Yunchun et al. 2018 [30] described that during effective treatment with biologic drugs of different categories, serum levels of calprotectin were diminished. Additionally, they noticed that responders to biologics had a major reduction in calprotectin levels 4 weeks after receipt of treatment, while non-responders did not express this effect.

Another crucial objective of the present study was to investigate a likely correlation between serum calprotectin levels and DAS28 both at baseline and 3 months after initiating bDMARDs. Definitely, no relationship was detected between both parameters (Table 2). Concomitant with our result, Smith et al. [31] found no statistically significant association between serum calprotectin levels and DAS28 at baseline or during follow-up. In contrast, Aghdashi et al. [32] from a cross-sectional study and Wang et al. [33] from a retrospective study found a significant correlation between serum calprotectin levels and DAS28 among their study cohort $(P=0.02$ and $P<$ 0.01 , respectively). Discrepancy of results could be attributed to different study designs from the existing one.

In an attempt to compare the diagnostic accuracy of serum calprotectin, CRP and ESR for discriminating patients with high and moderate disease activity, we plotted another ROC curve (Fig. 5). Unfortunately, calprotectin and ESR showed poor discrimination (AUC $=0.608$ and 0.579 , respectively), whereas CRP showed an $\mathrm{AUC}=0.704$, indicating acceptable performance.

In the entire RA cohort, different response patterns to biologic therapy were observed where $4 \%$ demonstrated good response, $72 \%$ moderate response and $24 \%$ did not respond to biologic therapy. In our study, we targeted to specify whether serum calprotectin can predict response to bDMARDs or not. In an attempt to establish such a likely association, Kruskal-Wallis test was done. Unexpectedly, no significant correlation was detected neither before $(\mathrm{P}=0.526)$ nor after receipt of bDMARDs $(P=0.746)$ in our 3 identified EULAR response phenotypes. A similar conclusion was also drawn by Smith and his co-investigators [31], where no clue of association between calprotectin concentration and EULAR response to etanercept was detected (non-responders versus moderate responders, $P=$ 0.957; and non-responders versus good responders, $P=$ 0.316). Moreover, Tweehuysen et al. concluded that no supplementary prognostic value of serum calprotectin was proposed for treatment response to adalimumab or etanercept in their group of RA patients [34].

In contrast to the present data, an earlier study by Choi et al. confirmed that serum calprotectin levels can powerfully foresee the response to biological therapy in RA patients [35]. Likewise, Nair and his co-workers emphasized that by means of circulating calprotectin levels coupled with clinical predictors, it is possible to tailor treatment regimens for RA patients initiating biologic therapy which can subsequently amplify the cost-benefit [36].

Indeed, our study has some limitations that worthmentioning. First, given the high cost of biological therapy, our study included a relatively small sample size. Second, no follow-up samples were collected from our cohort, so we were unable to detect changes of serum calprotectin levels over time. Finally, the results of this 
study reflect a single-center experience, which may interfere with the globalization of the current findings.
Received: 19 August 2021 Accepted: 25 October 2021

Published online: 07 December 2021

\section{Conclusions}

Overall, our study disclosed that serum calprotectin level was not valid in differentiating RA cases with moderate disease activity from cases with high disease activity as there was no significant correlation between serum calprotectin level and DAS28 score. More importantly, baseline serum calprotectin level had no significant association with response to biological therapy. Therefore, serum calprotectin could not be used as a predictor for clinical response to biological therapy in patients with RA. Hereafter, further studies including larger cohort of RA patients should be considered to validate the findings of the present work.

\section{Abbreviations \\ RA: Rheumatoid arthritis; bDMARDs: Biologic disease-modifying anti-rheu- matic drugs; DAS28: 28 Joint Count Disease Activity Score; EULAR: European League Against Rheumatism; ROC curve: Receiver operating characteristic curve.}

\section{Acknowledgements}

To all the patients and control subjects who participated in the current study.

\section{Authors' contributions}

RA (the corresponding author) proposed the point of research and was involved in writing the manuscript. AF extracted the relevant data from the patients and control subjects and performed the laboratory investigations mainly serum calprotectin evaluation. EH was involved in assessing the patients and participated in analyzing the data. TO participated in data extraction and analysis. All authors have read and approved the manuscript.

\section{Funding}

The study had no funding from any resource.

\section{Availability of data and materials}

The data used to support the findings of this study are available from the corresponding author upon request.

\section{Declarations}

\section{Ethics approval and consent to participate}

The study was conducted in accordance with the Declaration of Helsinki. The study design was approved by the local institutional review board (IRB) of the Faculty of Medicine, Mansoura University, Egypt (Approval No. MS. 18.07.207). A written informed consent was obtained from all participants prior to their enrollment. Confidentiality and personal privacy were respected in all levels of the study.

\section{Consent for publication}

Not applicable.

\section{Competing interests}

The authors declare that they have no competing interests.

\section{Author details}

${ }^{1}$ Department of Medical Microbiology and Immunology, Faculty of Medicine, Mansoura University, Mansoura, Egypt. ${ }^{2}$ Department of Pathological Sciences, Fakeeh College for Medical Sciences, Jeddah 2537, Kingdom of Saudi Arabia. ${ }^{3}$ Department of Rheumatology and Rehabilitation, Faculty of Medicine, Mansoura University, Mansoura, Egypt.

\section{References}

1. Smolen JS, Aletaha D, McInnes IB (2016) Rheumatoid arthritis. Lancet Lond Engl 388:2023-2038

2. Scherera HU, Häupl T, Burmester GR (2020) The etiology of rheumatoid arthritis. J Autoimmun 110:102400

3. de Brito RS, Baldo DC, Andrade LEC (2019) Clinical and pathophysiologic relevance of autoantibodies in rheumatoid arthritis. Adv Rheumatol 59:2

4. Aletaha D, Smolen JS (2018) Diagnosis and management of rheumatoid arthritis: a review. JAMA 320(13):1360-1372

5. Abbasi M, Mousavi MJ, Jamalzehi S, Alimohammadi R, Bezvan MH, Mohammadi $\mathrm{H}$ et al (2019) Strategies toward rheumatoid arthritis therapy; the old and the new. J Cell Physiol 234(7):10018-10031

6. Ho CTK, Mok CC, Cheung TT, Kwok KY, Yip RML, Hong Kong Society of Rheumatology (2019) Management of rheumatoid arthritis: 2019 updated consensus recommendations from the Hong Kong Society of Rheumatology. Clin Rheumatol 38(12):3331-3350

7. Papadopoulos CG, Gartzonikas IK, Pappa TK, Markatseli TE, Migkos MP, Voulgari PV et al (2019) Eight-year survival study of first-line tumour necrosis factor a inhibitors in rheumatoid arthritis: real-world data from a university centre registry. Rheumatol Adv Pract 3(1):rkz007

8. Wakabayashi H, Kino H, Kondo M, Yamanaka K, Hasegawa M, Sundo A (2019) Efficacy of subcutaneous tocilizumab in patients with rheumatoid arthritis and systemic sclerosis overlap syndrome: a report of two cases and review of the literature. BMC Rheumatol 3:15

9. Tavakolpour S, Alesaeidi S, Darvishi M, GhasemiAdl M, Darabi-Monadi S, Akhlaghdoust M et al (2019) A comprehensive review of rituximab therapy in rheumatoid arthritis patients. Clin Rheumatol 38(11):2977-2994

10. Ozen G, Pedro S, Schumacher R, Simon TA, Michaud K (2019) Safety of abatacept compared with other biologic and conventional synthetic disease-modifying antirheumatic drugs in patients with rheumatoid arthritis: data from an observational study. Arthritis Res Ther 21:141

11. Ruscitti P, Masedu F, Alvaro S, Airò P, Battafarano N, Cantarini L et al (2019) Anti-interleukin-1 treatment in patients with rheumatoid arthritis and type 2 diabetes (TRACK): A multicentre, open-label, randomised controlled trial. PLoS Med 16(9):e1002901

12. Sepriano A, Kerschbaumer A, Smolen JS, van der Heijde D, Dougados M, van Vollenhoven R et al (2020) Safety of synthetic and biological DMARDs: a systematic literature review informing the 2019 update of the EULAR recommendations for the management of rheumatoid arthritis. Ann Rheum Dis 79(6):760-770

13. Bergman MJ, Kivitz AJ, Pappas DA, Kremer JM, Zhang L, Jeter A et al (2020) Clinical utility and cost savings in predicting inadequate response to anti-TNF Therapies in Rheumatoid Arthritis. Rheumatol Ther 7:775-792

14. Nouri B, Nair N, Barton A (2020) Predicting treatment response to IL6R blockers in rheumatoid arthritis. Rheumatol 59(12):3603-3610

15. Nordal HH, Brokstad KA, Solheim M, Halse A-K, Kvien TK, Hammer HB (2017) Calprotectin (S100A8/A9) has the strongest association with ultrasound-detected synovitis and predicts response to biologic treatment: results from a longitudinal study of patients with established rheumatoid arthritis. Arthritis Res Ther 19:3

16. Inciarte-Mundo J, Ramirez J, Hernández MV, Ruiz-Esquide V, Cuervo A, Cabrera-Villalba SR et al (2018) Calprotectin strongly and independently predicts relapse in rheumatoid arthritis and polyarticular psoriatic arthritis patients treated with tumor necrosis factor inhibitors: a 1-year prospective cohort study. Arthritis Res Ther 20:275

17. Kopeć-Mędrek M, Widuchowska M, Kucharz EJ (2016) Calprotectin in rheumatic diseases: a review. Reumatologia 54(6):306-309

18. Jarlborg M, Courvoisier DS, Lamacchia C, Prat LM, Mahler M, Bentow C et al (2020) Serum calprotectin: a promising biomarker in rheumatoid arthritis and axial spondyloarthritis. Arthritis Res Ther 22:105

19. Aletaha D, Neogi T, Silman AJ, Funovits J, Felson DT, Bingham CO 3rd et al (2010) 2010 Rheumatoid arthritis classification criteria: an American College of Rheumatology/European League Against Rheumatism collaborative initiative. Arthritis Rheum 62(9):2569-2581

20. Erdfelder E, Faul F, Buchner A (1996) GPOWER: A general power analysis program. Behav Res Methods Instrum Comput 28:1-11 
21. Mansour HE, Abdullrhman MA, Mobasher SA, El Mallah R, Abaza N, Hamed F et al (2017) Serum calprotectin in rheumatoid arthritis: a promising diagnostic marker, how far is it related to activity and sonographic findings? J Med Ultrasound 25(1):40-46

22. van Riel PL, Renskers L (2016) The Disease Activity Score (DAS) and the Disease Activity Score using 28 joint counts (DAS28) in the management of rheumatoid arthritis. Clin Exp Rheumatol 34(5 Suppl 101):S40-S44

23. Tweehuysen $L$, den Broeder $N$, van Herwaarden $N$, Joosten LAB, van Lent $\mathrm{PL}$, Vogl T et al (2018) Predictive value of serum calprotectin (S100A8/ A9) for clinical response after starting or tapering anti-TNF treatment in patients with rheumatoid arthritis. RMD Open 4(1):e000654

24. Jarman KH (2013) The art of data analysis: how to answer almost any question using basic statistics. Wiley, Hoboken

25. Singh JA, Saag KG, Bridges SL, Akl EA, Bannuru RR, Sullivan MC et al (2016) 2015 American College of Rheumatology guideline for the treatment of rheumatoid arthritis. Arthritis Rheum 68:1-26

26. González-Álvaro I, Ortiz AM, Seoane IV, García-Vicuña R, Martínez C, Gomariz RP (2015) Biomarkers predicting a need for intensive treatment in patients with early arthritis. Curr Pharm Des 21:170-181

27. Adel N, William M, Al Swaff R, Hassan H (2014) Serum calprotectin level for diagnosis and detection of disease activity in rheumatoid arthritis. Int J Immunol 2:6-10

28. Zhang Z, Cai Y, Bai G, Zhang C, Li W, Yang B et al (2020) The value of calprotectin in synovial fluid for the diagnosis of chronic prosthetic joint infection. Bone Joint Res 9(8):450-457

29. Choi IY, Gerlag DM, Holzinger D, Roth J, Tak PP (2014) From synovial tissue to peripheral blood: myeloid related protein $8 / 14$ is a sensitive biomarker for effective treatment in early drug development in patients with rheumatoid arthritis. PLoS One 9(8):e106253

30. Yunchun L, Yue W, Jun FZ, Qizhu S, Liumei D (2018) Clinical significance of myeloid-related protein $8 / 14$ as a predictor for biological treatment and disease activity in rheumatoid arthritis. Ann Clin Lab Sci 48:63-68
31. Smith SL, Plant D, Eyre S, Hyrich K, Morgan AW, Wilson AG et al (2017) The predictive value of serum S100A9 and response to etanercept is not confirmed in a large UK rheumatoid arthritis cohort. Rheumatol 56(6):1019-1024

32. Aghdashi MA, Seyedmardani S, Ghasemi S, Khodamoradi Z (2019) Evaluation of serum calprotectin level and disease activity in patients with rheumatoid arthritis. Curr Rheumatol Rev 15(4):316-320

33. Wang Y, Liang Y (2019) Clinical significance of serum calprotectin level for the disease activity in active rheumatoid arthritis with normal C-reactive protein. Int J Clin Exp Pathol 12(3):1009-1014

34. Tweehuysen $L$, den Broeder $N$, Joosten $L A B$, Vogl T, van den Hoogen FHJ, Thurlings R, et al (2017) No added predictive value of serum calprotectin for treatment response to adalimumab or etanercept in ra patients [abstract]. Arthritis Rheum 69 (suppl 10). https://acrabstracts.org/abstr act/no-added-predictive-value-of-serum-calprotectin-for-treatmentresponse-to-adalimumab-or-etanercept-in-ra-patients/. Accessed 29 July 2021

35. Choi IY, Gerlag DM, Herenius MJ, Thurlings RM, Wijbrandts CA, Foell D et al (2015) MRP8/14 serum levels as a strong predictor of response to biological treatments in patients with rheumatoid arthritis. Ann Rheum Dis 74:499-505

36. Nair SC, Welsing PMJ, Choi IYK, Roth J, Holzinger D, Bijlsma JWJ et al (2016) A personalized approach to biological therapy using prediction of clinical response based on MRP8/14 serum complex levels in rheumatoid arthritis patients. PLoS One 11:1-12

\section{Publisher's Note}

Springer Nature remains neutral with regard to jurisdictional claims in published maps and institutional affiliations.

\section{Submit your manuscript to a SpringerOpen ${ }^{\circ}$ journal and benefit from:}

- Convenient online submission

- Rigorous peer review

- Open access: articles freely available online

- High visibility within the field

- Retaining the copyright to your article

Submit your next manuscript at $\boldsymbol{\nabla}$ springeropen.com 